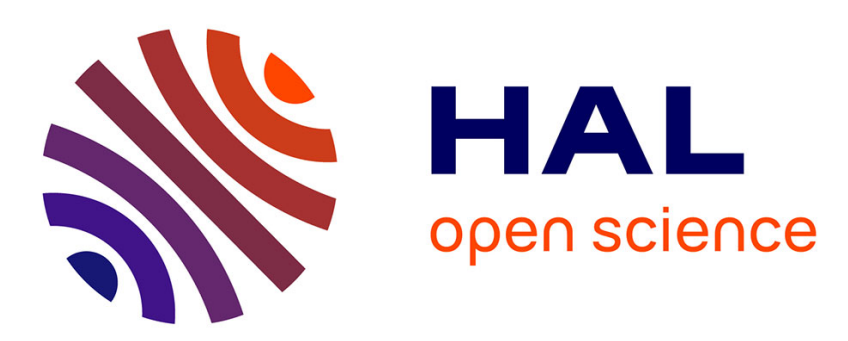

\title{
Compact self-directional antenna based on a helical ring
}

Bernard Souny, Christophe Morlaas, Alexandre Chabory

\section{To cite this version:}

Bernard Souny, Christophe Morlaas, Alexandre Chabory. Compact self-directional antenna based on a helical ring. APS/URSI 2010, Antennas and Propagation Society International Symposium, Jul 2010, Toronto, Canada. pp 1-4, 10.1109/APS.2010.5561226 . hal-01022226

\section{HAL Id: hal-01022226 \\ https://hal-enac.archives-ouvertes.fr/hal-01022226}

Submitted on 23 Sep 2014

HAL is a multi-disciplinary open access archive for the deposit and dissemination of scientific research documents, whether they are published or not. The documents may come from teaching and research institutions in France or abroad, or from public or private research centers.
L'archive ouverte pluridisciplinaire $\mathbf{H A L}$, est destinée au dépôt et à la diffusion de documents scientifiques de niveau recherche, publiés ou non, émanant des établissements d'enseignement et de recherche français ou étrangers, des laboratoires publics ou privés. 


\title{
COMPACT SELF-DIRECTIONAL ANTENNA BASED ON A HELICAL RING
}

\author{
B. Souny, C. Morlaas*, and A. Chabory \\ ENAC, CNS Department, 7 av E. Belin, 31055 Toulouse, France, \\ souny@enac.fr, morlaas@recherche.enac.fr, chabory@enac.fr.
}

\section{Introduction:}

In portable wireless devices, antennas have to respect several severe criteria. They must be compact, have a low sensitivity to their surroundings, and thus have controlled directional radiating characteristics. Circular polarization may also be an important concern. Such criteria exist for RFID antennas [1], mobiles handsets that must respect SAR constraints [2], or positioning systems (GPS, GALILEO, GLONASS). Few designs achieve to meet all these criteria. For instance, a wellknown technique to achieve directivity is to use antennas with reflectors of size at least a quarter of wavelength. But in addition to their large sizes, such antennas are sensitive to their environments.

In this paper we propose a new structure of antenna that is self-directional (without reflector) and has a low sensitivity to its surrounding. The direction of the radiation pattern can be electrically commutated on one side or on the other side of the antenna. The polarization can be chosen right or left circular. The size of the antenna can be strongly reduced. Furthermore, This antenna can be used at low frequency because high-permitivity dielectrics are not used for reducing the size.

\section{Principle:}

To obtain directivity we want to combine two radiating modes, both with a torus radiation pattern and a circular polarization. We assume that the first torus is oriented along the $x$-axis, whereas the second is oriented along the $y$-axis. If there is a phase shift of \pm 90 degrees between them, one can prove that the radiation will be null, resp. maximal, in the direction $+O z$ and maximal, resp. null, in the direction $-O z$. The position of the null and maxima depends on the sign of the phase shift. To obtain the first radiating mode with a torus radiation pattern and a circular polarization, a solution consists in a magnetic and an electric dipoles collocated and aligned on the $x$-axis. These magnetic and electric dipoles can be created with an helical antenna verifying the Wheeler condition [4]. Thus, the two torus modes can be obtained via two helical antennas oriented along the $x$ and $y$ axis.

It is possible to collocate the two helical antennas by using a ring shape helical antenna with a turn number multiple of four to have a rotational invariance of 90 degrees. In Fig. 1 an exemple for an 8-turns design is given.

The frequency is matched by adjusting the size of the ring, the number of turns, and the height of the turns. Note that the antenna efficiency depends on the final size. As explained in [3], this size can be strongly reduced compared to a halfwavelength antenna. In [3], the authors have also shown that in such structures the field remains mainly confined inside the helical part. Hence the sensitivity of this antenna to its surrounding is low. According to $[4,5]$, circular polarization can be 


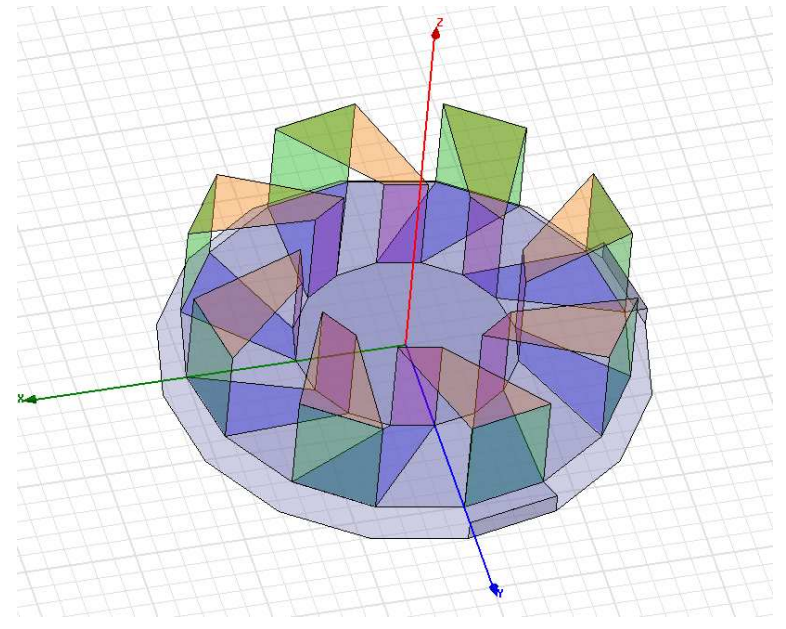

Figure 1: Design of the antenna

obtained for helices such that

$$
\pi \times \mathbf{D}=\sqrt{\mathbf{2} \times \mathbf{S} \times \lambda}
$$

in which $\mathbf{D}$ represents the diameter of the turn, $\mathbf{S}$ stands for the spacing between two turns, and $\lambda$ is the wavelength.

\section{Feeding:}

We use two feed probes placed on the $x$ and $y$-axis to excite the two orthogonal modes as illustrated in Fig. 1. The phase shift between both probes allow to control the direction of radiation. The sense of the circular polarization corresponds to the left-hand or right-hand orientation of the helix. Alternatively, only one feed probe can be used by adding an internal mode coupling to realize a quadrature excitation. The coupling element is then placed at $\pm 45^{\circ}$ from the position of the feed probe, with a \pm sign chosen to orient the radiation towards the direction $\pm O z$.

In this article, we use two feed probes that are electrically coupled to the antenna by means of a metallic disk placed below the ring. A magnetic coupling would also be possible using classical loops. Electric coupling is chosen here because it yields a simpler design.

\section{Simulation results:}

In this article we present an antenna of resonant frequency $2.07 \mathrm{GHz}$. The external and internal radius of the ring are $10 \mathrm{~mm}$ and $5 \mathrm{~mm}$, respectively. The height is set to $5 \mathrm{~mm}$. The external and internal widths of the turns are $3.9 \mathrm{~mm}$ and $1.95 \mathrm{~mm}$, respectively. The ring is placed $1 \mathrm{~mm}$ above a metallic disc of radius is $11 \mathrm{~mm}$.

The simulations are performed with Ansoft HFSS. We display in Fig. 2 the 3D radiation pattern for a phase shift of $-90^{\circ}$ between the probes. As expected, the antenna is directional, i.e. it only radiates towards the half space $z>0$. In Fig. 3, the polarization ratio of this antenna is plotted in the $x 0 z$ plane. We observe that 
the radiation is almost purely RHCP regarless the direction of observation.

According to the quadrature phase shift between the two feeds, positive or negative, the radiation pattern can be commutated from the half space $z>0$ to the half space $z<0$ (Fig. 4).

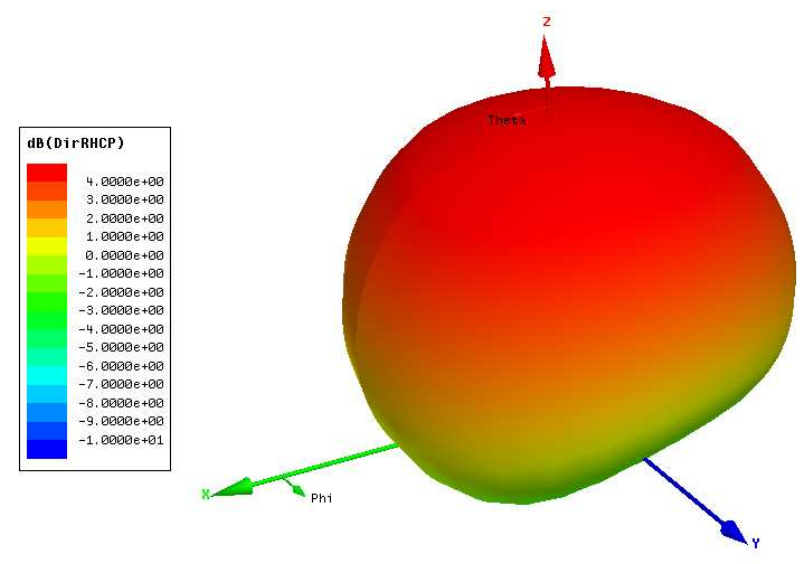

Figure 2: Directivity in $\mathrm{dBi}$ for a phase delay of $-90^{\circ}$ of the second probe with repsect to the first probe

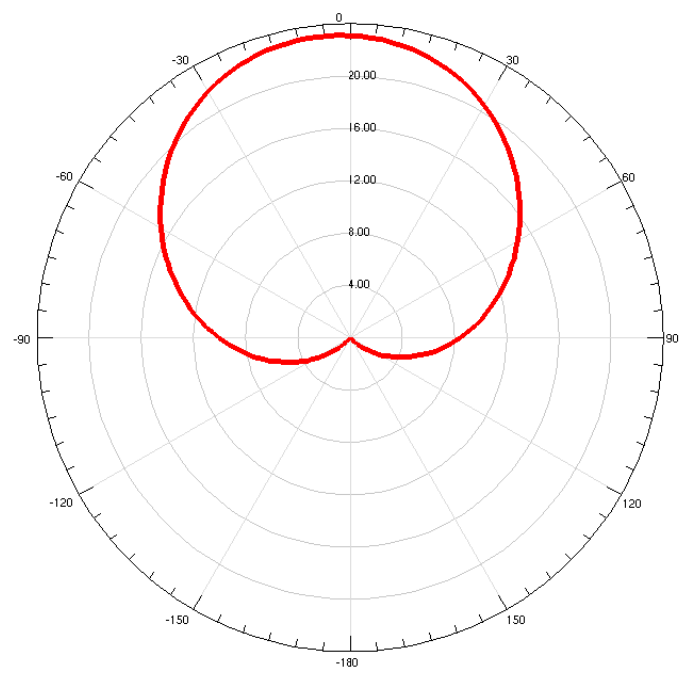

Figure 3: Polarization ratio $(\mathrm{RHCP} / \mathrm{LHCP})$ in $\mathrm{dB}$ in the $x 0 z$ plane $\left(\varphi=0^{\circ}\right)$

The characteristics of this new antenna are closed to the ones described in [3]. Its directivity is of $4.7 \mathrm{dBi}$. The efficiency is here of $82 \%$. Note that this result depends on the height and width of the turns. Indeed, the efficiency decreases when the turns becomes smaller. The bandwidth (defined from VSWR $<2$ ) is $14 \mathrm{MHz}$, which corresponds to $0.68 \%$. This value is influenced by the distance between the ring and the metallic disk. 


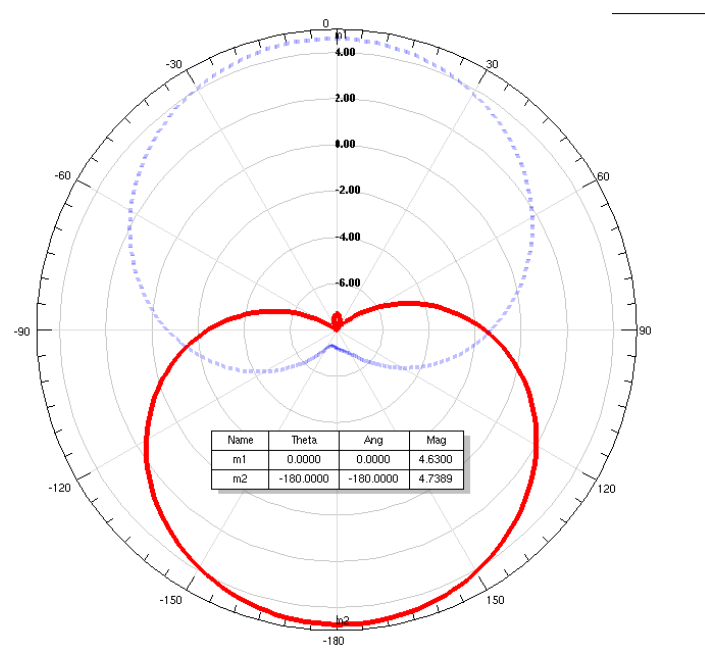

Figure 4: Directivity in $\mathrm{dBi}$ in the plane $\varphi=0^{\circ}$, phase delay of the second probe with respect to the first one: $-90^{\circ}$ (dashed line), $+90^{\circ}$ (solid line)

\section{Conclusion:}

A new structure of antenna is proposed to achieve a directional pattern and a circular polarization without reflector. The direction of the directivity can be easily commutated trough the feeding.

Since the electromagnetic fields are highly confined inside the helical part, this antenna presents a low sensitivity to its environment. Besides this antenna radiates only in a half space without any reflector. These two properties render this antenna highly adapted to be integrated into mobile devices or RFID sensors. Furthermore, in the half space where this antenna radiates, we have observed a very good circular polarization, which is attractive for satelite-based positioning systems as GPS, GLONASS, or GALILEO. Due to the capability of miniaturization, this kind of strucutre can also be interesting for network antennas.

\section{References}

[1] P.R. Foster, R.A. Burberry, "Antenna problems in RFID systems", RFID Technology (Ref. No. 1999/123), IEE Colloquium on, 1999.

[2] K.C.L. Kwok-Chi Chim Chan, R.D. Murch, "Investigating the impact of smart antennas on SAR", IEEE Transactions on Antennas and Propagation, Vol. 52, pp. 1370- 1374, May 2004.

[3] .M. Pigeon, C. Morlaas, H. Aubert, B. Souny, "Highly Compact Composite Antenna", Symp. IEEE-APS/URSI charleston, June 2009.

[4] H. A. Wheeler, "A helical antenna for circular polarization," Proc. of the I.R.E., Vo. 35, pp. 1484-1488, Dec. 1947.

[5] J. D. Kraus "The helical antenna", Proc. of the I.R.E., vol. 37, pp. 263-272, March. 1949. 